\title{
A construção televisiva do MMA: o programa TUF Brasil e o processo de humanização do lutador
}

The television construction of MMA: the TUF Brasil program and the fighter's humanization process

\author{
La construcción televisiva del MMA: el programa TUF Brasil y el proceso de humanización \\ del luchador
}

Flávio Py Mariante Neto ${ }^{a, *}$ (D), Daniel Giordani Vasques ${ }^{b}$ (D) , Marco Paulo Stigger ${ }^{c}$ (i)

Palavras-chave

MMA;

Esportivização;

Televisão;

Humanização.

\begin{abstract}
RESUMO
As artes marciais mistas (MMA) são um esporte criado e modificado em associação com a mídia, cujo principal expoente são os eventos do UFC. O objetivo foi descrever e analisar o programa televisivo The Ultimate Fighter (TUF) Brasil. A pesquisa caracterizou-se como um estudo de caso que empregou uma etnografia de tela, de forma a descrever e interpretar sentidos ali produzidos. A análise do reality show TUF Brasil construiu três categorias: o programa, estrutura e regras; as técnicas, treinos, lutas e estratégias de esportivização; e os dramas pessoais/familiares e o processo de "humanização" do lutador. O programa impulsiona o processo de esportivização do MMA ao aliar elementos técnico-táticos das lutas com narrativas e dramas dos sujeitos.
\end{abstract}

\section{Keywords}

MMA;

Sportization;

Television;

Humanization.

\begin{abstract}
Mixed martial arts (MMA) is a sport created and modified in association with the media, whose main exponent are UFC. The objective was to describe and analyze The Ultimate Fighter (TUF) Brazil. The research was characterized as a case study that used screen ethnography, in order to describe and interpret meanings. The analysis of TUF Brasil built three categories: the program, structure and rules; techniques, training, fights and sportization strategies; and the personal/family dramas and the "humanization" process of the fighter. The program boosts the sportization process of MMA by combining technical-tactical elements of the contests with the subjects' narratives and dramas.
\end{abstract}

\begin{abstract}
RESUMEN
Las artes marciales mixtas (MMA) son un deporte creado y modificado en asociación con medios de comunicación, cuyo principal exponente es el UFC. El objetivo fue describir y analizar el programa de televisión The Ultimate Fighter (TUF) Brasil. La investigación se caracterizó como estudio de caso que utilizó la etnografía en pantalla, con el fin de describir e interpretar los significados. El análisis construyó tres categorías: el programa, la estructura y las reglas; técnicas, entrenamientos, luchas y estrategias de deportización; y los dramas personales/ familiares y el proceso de "humanización" del luchador. El programa impulsa el proceso de deportización de MMA al combinar elementos técnico-tácticos de las luchas con las narrativas y dramas de los sujetos.
\end{abstract}

\footnotetext{
aUniversidade Luterana do Brasil, Departamento de Educação Física. Canoas, RS, Brasil.

'Universidade Federal do Rio Grande do Sul, Colégio de Aplicação, Departamento de Expressão e Movimento. Porto Alegre, RS, Brasil. 'Universidade Federal do Rio Grande do Sul - UFRGS, Programa de Pós-Graduação em Ciências do Movimento Humano. Porto Alegre, RS, Brasil.
}

\footnotetext{
*Autor correspondente:

Flávio Py Mariante Neto

E-mail: flaviomariante@hotmail.com
} 


\section{INTRODUÇÃO}

As associações entre o esporte e os meios de comunicação, especialmente a televisão, têm caráter de interesse mútuo, de modo que o esporte tem grande alcance ao ocupar boa parte da programação televisiva, bem como é um de seus produtos mais rentáveis. A aproximação entre tais campos, de acordo com Bourdieu (1997), visa à produção e ao consumo de produtos e também de bens simbólicos, que são aqueles que exigem a decifração e intencionam a apropriação e incorporação.

Nesse sentido, faz-se fundamental considerar que a produção esportiva na televisão se dá para além do jogo, envolvendo outros elementos éticos, comportamentais e pessoais dos atores. Nesse caminho, boa parte da produção do "jornalismo esportivo", como salientam Coche e Tuggle (2017), se detém às histórias sobre as "estrelas" esportivas e sobre as histórias de fundo (background), mostrando, assim, que a produção midiática no esporte ultrapassa os limites do jogo e constrói narrativas sobre o entorno esportivo.

As artes marciais mistas (MMA) são um esporte construído nos anos 1990 a partir de, como indica Vasques (2013), incrementos de esportivização de modalidades de lutas com poucas regras, distanciando-se, assim, de elementos considerados violentos (sangue, batalhas, jaulas) e introduzindo características das modalidades esportivas de lutas (tempo, round, peso, golpes proibidos, árbitro, etc.). A construção social de tal modalidade esportiva se deu - como indicam Awi (2012) e Spencer (2009) -, de forma análoga a seu tempo histórico, por uma empresa privada (Ultimate Fighting Championship, UFC) e pela preocupação com a construção e transmissão de espetáculos televisivos. Nesse sentido, o MMA é uma modalidade construída e firmada por duas características distintivas das modalidades esportivas tradicionais: a associação desde a concepção com a mídia e o espetáculo, bem como a organização e comando por uma empresa privada, e não por uma federação esportiva como é de costume nesse campo.

Um dos produtos (televisivos) construídos pelo UFC é a produção e transmissão de um reality show composto por lutadores e treinadores, os quais disputam um contrato de trabalho junto à tal empresa, o que Ihes permite lutar nos eventos, também chamados de UFC ${ }^{1}$. Tal reality denomina-se The Ultimate Fighter (TUF). O programa já conta, no total, com 28 edições. No Brasil, realizaram-se três temporadas, as quais foram transmitidas pelo canal de televisão Globo nos domingos à noite. O UFC passou por uma crise financeira nos anos 2000 (Awi, 2012) com a diminuição de público. O discurso de violência, o sangue nas disputas e a falta de entendimento aumentavam sua rejeição. Em vários estados norte-americanos, o MMA era proibido. Essa repulsa é considerada como um dos indicativos para

1 A sigla designa a empresa e o evento de lutas. que o UFC criasse um programa de TV com o intuito de aproximar os espectadores. Assim, foi desenvolvido um reality show que mostra as rotinas dos lutadores e seus dramas para o público.

Com base nas construções de Bourdieu (1983), a posição que o MMA ocupa no campo esportivo e no subcampo das lutas é fruto das disputas, lutas e concorrência pela hegemonia no campo. Nesse sentido, o emprego de um programa no formato de reality show mostra-se uma estratégia interessante pois, conforme afirma McClearen (2017, p. 3230) em análise do TUF estadunidense, tal tipo de programa "[...] se presta a criar drama em torno de um esporte de combate". Segundo esse autor, os produtores e criadores estabelecem a "realidade" como representações do "real" e do "autêntico"; no entanto, grande parte do trabalho de criação de um episódio ou temporada depende de drama ou intriga, editando inúmeras horas de filmagem para criar uma história concisa e colocando pessoas "reais" em situações artificiais. Nessa lógica, não é possível entender o TUF como realidade, mas antes como uma produção televisiva que se utiliza de determinados elementos reais e espontâneos.

Ao analisar a produção científica sobre lutas e MMA, pode-se observar que trabalhos como os de Wacquant (2002), Nunes (2004), Gastaldo (2001) e Spencer (2009) trazem elementos muito ricos dos processos de construção do lutador. A "forja" a que esses trabalhos tanto se referem é relativa a processos que se constroem especialmente dentro das academias e dos ringues, nos treinamentos e nas lutas. Porém, a análise do TUF Brasil exige noticiar que a forja se dá 'para além da academia', ou seja, há elementos intencionais, do UFC e de sua relação simbiótica com a televisão, de construção do lutador e de configuração de uma modalidade que procuram distanciar do telespectador a violência, a brutalidade e o corpo como máquina (dos atores, da modalidade, do programa), bem como buscam aproximar elementos que raramente estão presentes na análise dessa modalidade, como os sentimentos, os choros, as rezas, os sonhos.

Os interesses dessa pesquisa residem na análise de um programa televisivo de MMA enquanto produtor de sentidos para o esporte, ou seja, a partir da relação entre esporte e mídia no caso em questão, propõe-se levantar elementos para a compreensão daquela modalidade esportiva. Sendo assim, o objetivo desse estudo foi descrever e analisar o programa televisivo The Ultimate Fighter Brasil.

No texto a seguir, são descritos a estrutura do programa, as rotinas de treino e lutas. Também se apresentam alguns dramas relacionados à origem, à família, à reza. As análises retratam o programa como um elemento do processo de esportivização da modalidade, em acordo com os sentidos desenvolvidos por Elias e Dunning (1992), e, em vista disso, indicam um processo de "humanização" do lutador, que o afasta 
de um conceito de "casca-grossa", ou "brutamonte", e aproxima-o da ideia de um esportista, um atleta; um ser humano que sofre, sente e aguenta duras rotinas com o objetivo de, normalmente, sair de sua precária situação social e ajudar sua família. Com esse movimento, o programa visa a alcançar a audiência de que necessita, e o UFC conquista mais adeptos e lucro na relação de interdependência (Elias, 2005) evento/mídia/lutador.

\section{MATERIAL E MÉTODOS}

Os caminhos metodológicos empregados na construção deste estudo foram a combinação do "estudo de caso" e da "etnografia de tela". O estudo de caso é reconhecido por autores como Yin (2005) e Stake (1994) que sustentam que um caso se configura como algo definido por uma decisão, por exemplo, no caso aqui considerado, a construção/realização e transmissão em rede de TV aberta de um programa que tem como cerne um reality show do MMA em suas dimensões de prática esportiva e de relações socioafetivas.

A etnografia de tela, por sua vez, foi apontada por Rial (2004) como um método que "transporta para o estudo do texto da mídia procedimentos próprios da pesquisa antropológica" (p.30). Nesse sentido, características tradicionais das etnografias como a longa imersão do pesquisador no campo (em frente à TV), a observação sistemática e a descrição densa em diários foram utilizadas para a produção de dados nessa pesquisa. Como característica analítica na produção etnográfica, procurou-se descrever e analisar os sentidos das cenas, imagens, focos, bem como das histórias e das narrativas produzidas e inseridas ao longo dos programas televisivos, com a intenção de, em acordo com Geertz (1989), interpretar os sentidos ali produzidos e codificados.

O programa TUF Brasil transmitido pelo canal de TV aberta Rede Globo de abril a agosto de 2015 foi o alvo dos registros. Esse programa se caracteriza pela aproximação que ele propõe do público com o esporte, mostrando rotinas de treinos e dramas na vida do atleta. Foram registrados em diários de campo 12 episódios de 60 minutos que formaram a temporada brasileira em questão.

Os estudos de Norbert Elias auxiliaram na análise dos elementos simbólicos de construção do lutador percebidos ao longo do programa. Assim, os entendimentos eliasianos sobre a diminuição da violência no processo civilizador (Elias, 2011) e sobre a transformação dos jogos e passatempos em esporte (Elias e Dunning, 1992) foram basilares para tais análises. A partir desses referenciais, buscou-se interpretar as intenções e sentidos atribuídos e construídos em torno do MMA, cuja configuração (Elias, 2005) é formada pelas academias e eventos esportivos, mas também pela mídia. As categorias de análise, apresentadas a seguir, foram construídas a partir dos dados de campo com base em um esforço de distanciamento reflexivo em relação a categorias pré-reflexivas, assim, procurou-se ser o menos parcial possível de forma a enxergar novos elementos dentro dessa construção.

\section{ESTRUTURAS, REGRAS E ROTINAS}

O primeiro episódio do programa pautou-se pela apresentação dos atletas e treinadores: Anderson Silva, ídolo do UFC; e Maurício Shogun, campeão do UFC e do Pride $^{2}$. Cada um era responsável por uma equipe de oito atletas. As regras eram: 32 lutadores disputam uma luta e os vencedores formam o quadro de atletas (16) que "entram na casa", ou seja, participam do reality show que, em cada episódio, tem uma ou duas lutas eliminatórias. Os dois finalistas de cada categoria de peso (galo até $66 \mathrm{~kg}$ e leve até $70 \mathrm{~kg}$ ) disputam a final em um evento do UFC em Las Vegas.

Os movimentos para aproximar o MMA dos sentidos de esporte buscam, ao mesmo tempo, distanciá-lo das lutas sem regras (Vasques, 2013). Esse percurso tem início nos anos 1990, quando foram inseridas regras no UFC para diminuir a percepção de violência, como categorias de peso, uso de luvas, duração do combate, além da proibição de diversos golpes. A diminuição da violência nos combates é parte de um processo de esportivização das lutas, e o UFC se preocupa com isso. As falas dos treinadores por diversas vezes visavam a distanciar a violência e aproximar comportamentos esperados de um "esportista". A configuração do MMA, assim, é construída também nas tensões sobre os reconhecimentos da nãoviolência e do lutador como profissional.

No segundo episódio, as oito lutas preliminares faltantes para "entrar na casa" são mostradas. A dinâmica é a seguinte: mostra-se o nome do lutador, a cidade e a família consanguínea, antes de ser mostrada a academia onde faz seus treinamentos. Os dois que lutarão são, então, conduzidos ao octógono por treinadores e observados por Anderson, Shogun e Dana White, o "dono do evento". Os dois primeiros escolherão seus times após estas lutas.

A dinâmica se repete e os lutadores vão sendo apresentados, primeiro, nas relações com as suas famílias e, após, nos seus treinamentos. Os treinadores analisam as lutas e fazem comentários técnicos sobre as razões das vitórias ou derrotas. Após os combates, são expostas entrevistas com os perdedores e ganhadores. No primeiro caso, o choro ganha destaque, como na situação de um lutador que, chorando copiosamente, declarou: "Fiquei muito triste [...], mas isso não é motivo para me abalar. Não vou desistir de lutar no UFC" (Episódio 1, 05/04/2015). Nas entrevistas após vitória, geralmente os lutadores dedicam-nas para a família: "Dei o meu melhor pela minha família"; "Eu dedico essa vitória a minha família"; "Dedico essa vitória ao meu irmão"; "Pela minha família, botei o meu coração na luva" (Ep.

\footnotetext{
2 Campeonato de vale-tudo.
} 
2, 12/04/2015); entre outras com sentido próximo que se repetiram no programa.

O episódio 3 (19/04/2015) apresenta a entrada dos lutadores na casa do TUF, onde os atletas ficam hospedados durante o programa. A casa é enorme; tem vários quartos distribuídos em dois andares. Há uma grande sala de estar na entrada, antecedida por um jardim e uma piscina; uma sala de jogos com sinuca e outros. A casa impressiona pelo tamanho e luxo; característica ressaltada pelos lutadores, que descrevem a grandiosidade e confirmam que participar do programa é uma "grande oportunidade". Um deles diz: "Nunca estive em um lugar assim. Para mim é um sonho". A próxima imagem é de um grito de guerra entoado por alguns participantes, que, enfileirados e abraçados na sala, gritam: "Uhul, a casa é nossa" algumas vezes. A grandiosidade do centro de treinamento (CT) também é ressaltada. A academia é luxuosa, tem equipamentos de última geração, tatames, aparelhos de musculação, sacos de pancada e um ringue. Nesse momento, aparece o primeiro treino, da equipe vermelha (Shogun). Ao entrar no CT, é visível a exaltação do espaço como uma "academia perfeita para treinar", segundo um atleta.

A casa do TUF e o CT dão o "clima de sonho" destacado pelos atletas. O UFC vai se mostrando um local de desejo, aonde se quer chegar. Os lutadores são levados a um cassino em Las Vegas para uma noite de jogos, bebidas e festas. Os lutadores aparecem bebendo, jogando e aproveitando a noite no cassino.

Um fato importante no programa foi a notícia de doping de Anderson Silva. O programa mostrou a reação do atleta quando recebeu uma ligação na qual estaria sabendo do resultado adverso. A cena mostra a indignação de Anderson; sua reação é de negação e suas frases supõem um erro: "Não tomei nada disso. Tomei injeção de anti-inflamatório. Nunca na minha vida tomei nada disso" (Ep. 3, 19/04/2015). Ao desligar, ele conversa com seu preparador físico, que lhe diz para não se preocupar, pois "tudo vai se resolver".

O antidoping parece ser um dos principais mecanismos de busca de uma pureza como se fosse uma "essência", espécie de "natureza" do esporte. Diversas instâncias tratam a pureza como um princípio do esporte, espelhadas nos valores do olimpismo de Coubertin. Douglas (2014), ao refletir sobre a dualidade puro-impuro, propõe a pureza como categoria relacional, assim, ela é procurada na mesma ordem que a impureza é evitada. A impureza é essencialmente desordem, o que sugere a busca do puro por meio de rituais - e os testes antidoping ocupam esse lugar. A noção de perigo advém do contato com o impuro e é importante critério de distanciamento da pureza. Nesse sentido, o desvio, a doença e a sujeira - em contraste à normalidade, à saúde e à limpeza - entram como formas de poluição e de afastamento da pureza.

A busca de uma pureza no esporte parece ser objetivo não somente das ações antidopagem. $O$ controle da violência, seja no campo ou nas torcidas, os tribunais, o controle e fiscalização de resultados combinados, a burocratização, entre outros, também parecem ser formas de buscar um esporte puro. A pureza aparece no mundo esportivo sob diferentes representações na forma de objetos, símbolos, corpos e entidades. Há também diferentes processos de busca da pureza que ocorrem no campo esportivo, que parecem desejar um ordenamento e afastamento das formas de impureza criadas. A partir das representações de sujeira e poluição, procura-se um ordenamento necessário representado na forma de processos de purificação.

A construção de uma imagem de esporte para o MMA é intencional e evidente. A exclusão de Anderson Silva demonstra que a pureza intencionada pelo esporte se coaduna com as ideias passadas pelo MMA. Isso é muito representativo, pois o atleta era considerado pelo próprio UFC o maior "peso por peso" de todos os tempos. A entidade, ao mostrar no programa consequências para um atleta dessa importância, demonstra interesse em construir uma imagem de esporte, de seriedade, ética e justiça.

A seguir, são apresentadas as rotinas de treino como elementos de distanciamento da violência e de aproximação com os significados atribuídos ao esporte.

\section{TREINOS E ESTRATÉGIAS DE ESPORTIVIZAÇÃO}

As dinâmicas de treino obedeciam a uma lógica comum dentro das lutas. Várias artes marciais (boxe, muay thai, wrestling e jiu-jitsu) eram misturadas e aprimoradas. Quando não tinham lutas marcadas, os atletas treinavam uma mistura de lutas. Quando a luta se aproximava, as especificidades do lutador eram trabalhadas, assim como eram definidas estratégias de combate a partir das especialidades dos adversários. Aqueles oriundos da luta agarrada treinavam para "levar para o chão"; em contrapartida, os strikers ${ }^{3}$ treinavam para manter a luta em pé.

O cenário de contenda entre as equipes vai dando um clima de disputa para a série. Não apenas as técnicas e estratégias, mas também a rivalidade entre as equipes vermelha e azul dá a voga do programa. Em dado momento, o Time Shogun liderava as lutas por $4 \times 0$ contra o Time Nogueira. Em razão das derrotas, no capítulo 7 (18/05/2015) os lutadores aparecem cabisbaixos e tristes nos treinamentos. Seus treinadores dizem que "é hora de reagir", e que têm que ter "olho de tigre". Minotauro dá orientações sobre o treino do dia em que o foco será um "MMA de explosão", com "chutes, joelhadas e entradas de quedas."

Durante um treinamento, alguns atletas "pegam mais pesado" e há um começo de confusão entre os lutadores. Os técnicos interrompem o treinamento

3 Nocauteadores. 
para acalmar os ânimos. Um deles diz: "Quero vocês concentrados e de cabeça fria, não é pra machucar ninguém" (Ep. 5, 04/05/2015). Minotauro comenta: "Tá tudo tranquilo; o que rola no tatame, fica no tatame." As separações entre briga e luta foram alvo de estudos (Cecchetto, 2004), e são parte intencional dos processos de esportivização do MMA (Vasques, 2013) e de "humanização" do lutador. A expressão nativa "quem luta, não briga" sugere que essa etiqueta é parte da rotina dos lutadores. Assim, lutar estaria relacionado às atividades dentro da academia, incluídas regras e normas; enquanto a briga se refere ao confronto desregrado, em razão de desentendimentos ou discussões, e deve ser evitada. Dessa forma, o jogo esportivo deve se limitar ao espaço do octógono, e o descontrole controlado, indicado por Elias e Dunning (1992), só é válido ali. O processo de esportivização exige que os lutadores incorporem esse modo de agir e não ultrapassem essa barreira.

Nesse sentido, a luta entre amigos é assunto controverso. Alguns ressaltam que é difícil "sair na porrada" com alguém com quem se treine ou conviva. Outros defendem, entre eles o UFC, que, por ser um esporte e ficar "dentro do ringue", não haveria problemas em "casar lutas" entre parceiros de treino. Longe de se ter unanimidade, no TUF alguns parceiros de treino lutaram entre si, pois, nas regras do programa, os atletas não escolhem seus oponentes; essa escolha é dos treinadores. Essa parece ser mais uma estratégia de esportivização do MMA. Colocar dois amigos para lutar significa que há interesse em desvincular o esporte da violência, ou da "rixa", marcantes nas antigas disputas entre academias.

Até aqui, observam-se processos de desvinculação e afastamento da violência para com os lutadores, em consonância com aquilo que Elias e Dunning (1992) caracterizam como esporte, ou esportivização, que foram construídos a partir da identificação das rotinas de treinamento e dos combates. Tal noção foi instituída a partir do exemplo da transformação do caça à raposa em esporte, onde os autores mostraram como o deslocamento da tensão-excitação se dá do prazer em matar e comer o animal para o fazer com que os cães matem as raposas. Esse movimento de deslocar a prática da violência para o ato de assistir a violência sendo praticada ocorre a partir de um aumento na intolerância à violência e na sensibilidade.

O esporte, enfim, é uma das maiores invenções humanas não planejadas que vive, assim, uma tensão entre prazer e restrição. Controles sobre o comportamento das pessoas, formação da consciência, interiorização das regras garantem mais segurança às pessoas, no entanto, implicam em perda das satisfações agradáveis associadas a comportamentos mais simples e espontâneos. 0 processo de esportivização, no sentido eliasiano, vem sendo efetivado no MMA, entre outros elementos, também pelo que denominamos de "humanização do lutador", a qual, nesse sentido, se caracteriza por um incremento na interiorização, no controle e na consciência, o qual é, como dito, parte do processo de esportivização do MMA.

A noção de "humanização do lutador" é, primeiramente, uma expressão nativa do campo, na medida em que o próprio UFC a utiliza para caracterizar as intenções com o programa TUF: "O programa conta a história de pessoas como eu, como você. [...] É a desmistificação do lutador, a humanização de um personagem blindado pelo estigma que carregavam os antigos gladiadores" (Ozório, 2020, n.p). Ao mesmo tempo, tal expressão se caracterizou também como uma categoria de análise construída a partir dos dados empíricos, tendo em vista que compreende determinados elementos do processo de esportivização do MMA empreendidos pelo programa em questão, especialmente aqueles que não estão relacionadas diretamente ao combate em si, e que, consequentemente, posicionam os lutadores em fazeres cotidianos e ordinários (rezar, comer, conversar, compartilhar dificuldades, etc.) e em situações de emoção aparente (choro, reza, esperança, sonho, etc.). O tópico em sequência se dedica a visualizar e a analisar tais elementos.

\section{A "HUMANIZAÇÃO DO LUTADOR": CHORO, SUPERAÇÃO, EMOÇÃO, AMIZADE E REZA}

Há forte apelo emocional no programa. O choro está presente em quase todos os episódios. Evocações à família e à amizade são reações marcantes da temporada. As lesões também são foco de algumas cenas. Soldado, por exemplo, foi cortado do programa por sofrer uma lesão grave no joelho. Um médico apareceu dando explicações: "O atleta não tem mais condições de lutar" (Ep. 8, 24/05/2015). O lutador surgiu chorando copiosamente enquanto arrumava as malas.

As histórias de vida também são exploradas. Nikolas aparece falando sobre seu passado, da vida em Manaus e diz que deixou a família "por causa desse sonho" (Ep. 6, 11/05/2015). Glaico ressalta a importância que o evento tem: "Entrar no UFC é um sonho para qualquer lutador. Todos os sacrifícios que eu já passei na vida vão valer à pena se eu conseguir a vaga" (Ep. 11, 15/06/2015). Mais uma vez, o UFC parece ser o ápice para os lutadores. Segue um registro de diário de campo referente a histórias de vida.

Pitbull ressalta [...] sua partida do Nordeste para realizar seu sonho no TUF: 'Deixei minha família toda em Mossoró, minha esposa e minha filha.' A câmera, a seguir, dá um close no lutador que começa a chorar. [...] Korea segue a mesma dinâmica [...]: 'meu pai abandonou a minha mãe, minha irmã tem problema no rim e precisa fazer uma operação e eu gostaria de ajudar.' Mais uma vez, o choro do atleta é mostrado em um ângulo fechado. O atleta finaliza, entre lágrimas: 'Vou ganhar e oferecer essa vitória para minha irmã que está doente.' (D.C. Ep. 7 18/05/2015). 
As passagens que antecediam as lutas eram permeadas por histórias de vida, geralmente tristes. Indivíduos que moravam em favelas em condições precárias; atletas para os quais o UFC chegaria como uma salvação. Famílias com problemas, pais doentes e irmãs com necessidades. Entretanto, apenas dois seriam contratados; os demais voltariam para casa, enfrentariam a realidade dura de uma carreira que quase se tornara reconhecida. Mas que, para a maioria, continuaria um "sonho". Entretanto, essa reflexão não é mostrada; vontade e superação parecem ser os únicos ingredientes. A exploração dos dramas pressupõe uma individualização que pouco condiz com a realidade. Por mais esforços que os atletas façam, a eliminação é latente e chegará a quase todos.

O TUF traz à cena elementos tradicionalmente ocultados ao se tratar de lutadores, mas comumente expostos pelos programas esportivos, como sentimentos, emoções, dramas. Assim, as cenas se alternam entre técnicas e sentimentos, entre estratégias de lutas e emoções, entre máquina e "humano", entre "natureza" e "cultura", como se técnicas e combates fossem executados por uma "natureza" do lutador, e este fosse "humanizado" a partir dos dramas, choros e ascensões sociais. O processo de "humanização" do lutador, nesse sentido, desloca para locais diferentes as técnicas e os choros, as lutas e os sonhos, como uma purificação dos sujeitos ao construir tal dualidade. A natureza se manifestaria em ser guerreiro lutador, o "humano" seria chorar, mostrar emoções.

Tal dualidade se mostra equivocada, primeiro ao dividir o sujeito, humano, em parte "máquina" e parte "humana", como se a humanidade não fosse exatamente a hibridez de tais polos. Ainda se apresenta desacertada ao não considerar a complexidade e variabilidade da produção cultural acumulada existente na execução de golpes, técnicas, estratégias de lutas. Assim, cabe reiterar que o lutador é produzido culturalmente tanto nas rotinas de treino, técnicas e estratégias e de lutas quanto nos dramas, choros e rezas. Sendo assim, propor o debate sobre a "humanização do lutador" não se trata de considerar parte de sua produção como "não humana", mas, ao contrário, entender que o programa deu visibilidade a sentimentos e dramas comuns aos sujeitos humanos como estratégia de aproximação com o público, em uma lógica de esportivização do MMA.

Os estudos de Latour (2019) sobre ciência e política auxiliam a interpretar a construção do lutador como um híbrido de máquina e humano, de natureza e cultura, de ciência e política. Para este autor, esses polos nunca estiveram verdadeiramente separados, mas sim ocultados. Com base em tais ideias, é possível considerar que as construções feitas pelo programa dos lutadores como seres híbridos ajudaram a vislumbrar, a ver, a dar foco a partes ("humanas") que sempre existiram, mas eram ocultadas, esquecidas, apagadas. Esses enfoques que têm a intenção de humanizar o lutador visam à aproximação de um público que se identifica com histórias de superação, choro, reza.

Nesse contexto, um ponto importante é a religiosidade. Como em muitos grupos esportivos, as equipes se reuniam antes e após as lutas para orações. Quase sempre em círculo, agradeciam e pediam. Dentro da casa, muitas vezes mostravam-se atletas rezando e pedindo ajuda de Deus nos combates. A religiosidade também é evocada nos resultados das lutas, como no excerto abaixo:

O juiz declara [...] vencedor ao fim do combate. Reginaldo diz que sua vitória teve 'as mãos de Deus' e Matheus diz: 'Reginaldo me venceu na garra. Teve mais coração.' (D.C. Ep. 9 01/06/2015).

Em um esporte circundado por discursos de brutalidade, agressivo e, nas mentes mais criativas, violento, essa preconização religiosa parece significar certa "salvação" do esporte. Acessar a religiosidade é aproximar a luta do público. Os pecados ficam diminuídos. A agressividade amaina. A intensidade abranda e as tensões se equilibram. O lutador luta, bate e apanha. Mas aparece rezando. É "humanizado". A configuração se mantém.

\section{CONCLUSÕES}

Essa pesquisa teve como objetivo descrever e analisar o programa TUF Brasil, o qual se caracteriza como um reality show no qual lutadores de MMA se enfrentam com vistas a um contrato para atuar como profissional no/pelo UFC. A pesquisa, caracterizada como um estudo de caso, utilizou para a produção de dados, de uma etnografia de tela, a qual elencou como instrumentos a observação e a descrição densa, bem como o registro em diários de campo.

O primeiro tópico apresentou a estrutura, as regras e a rotina do programa. Nesse contexto, foram elencados elementos que procuram exigir do atleta comportamentos que o distanciem da violência e o aproximem do esporte. Ainda, verificou-se a partir de um caso concreto em tela como o antidoping é uma instituição que busca uma pureza no esporte e como, nessa associação esporte-mídia, procura construir uma imagem de esporte para o MMA.

O segundo capítulo descreveu os treinamentos e analisou as estratégias de esportivização. A proposição de lutar "entre amigos", tema controverso no subcampo das lutas, incitou a reflexão sobre separação entre luta e briga, a qual é característica do esporte e pareceu ser uma estratégia do programa de esportivização do MMA. Ademais, as rotinas de treinamento, nas quais aparecem golpes, técnicas, repetição, ciência, estratégia, acabam por desvincular e afastar os sentidos de violência daquele espaço. Ao fim, verificamos que a "humanização do lutador" é uma expressão nativa do universo do MMA, bem como elevou-se a uma categoria de análise construída a partir dos dados de campo. 
Apelo emocional, choro, sofrer, chorando copiosamente, preocupação, aguentar, abraçam, lágrimas, emoção, histórias de vida, sonho, tristes, favelas, condições precárias, salvação, famílias, problemas, pais doentes e irmãs com necessidades, realidade dura, vontade, superação, dramas, sentimentos, emoções, histórias de superação, reza, religiosidade, agradeciam, pediam, presença de Deus, salvação. Todos os elementos aqui listados apareceram ao longo do terceiro tópico do texto, que apresentou cenas e propôs reflexões sobre a "humanização do lutador", a qual é parte do processo de esportivização do MMA construído no programa. Tal conceito busca compreender que o emprego de sentimentos, narrativas e dramas que são compartilhadas, comuns a sociedades humanas, bem como que tais interesses de distanciamento da violência e de aproximação com o público são partes de uma mesma lógica de esportivização do MMA.

O UFC se utiliza de dois ingredientes principais para aproximar-se do público: o primeiro ligado a questões que aproximam a luta da ideia de esporte; mostrar o treinamento, os tipos de gestos, as modalidades de cada atleta, a preparação para a luta e os processos muitas vezes dolorosos pelos quais os atletas passam. Porém, isso não seria suficiente se não fossem mostradas, também, as relações com a família, os dramas pessoais, a religiosidade. Esse contínuo intenciona a aceitação do público, que pode se sentir mais confortável ao entender que aquilo que, num primeiro olhar, parece sem sentido seja construído segundo os costumes de um processo civilizador de longo prazo. A intolerância à violência torna-se mais sólida. O MMA, então, adapta-se, cria estratégias e se mantém.

\section{FINANCIAMENTO}

O trabalho recebeu apoio financeiro no formato bolsa CAPES.

\section{CONFLITOS DE INTERESSE}

Os autores declaram não haver conflitos de interesse.

\section{REFERÊNCIAS}

Awi F. Filho teu não foge à luta: como os lutadores brasileiros transformaram o MMA em um fenômeno mundial. Rio de Janeiro: Intrínseca; 2012.

Bourdieu P. Questões de sociologia. Rio de Janeiro: Marco Zero; 1983. p. 136-153.
Bourdieu P. Sobre a televisão: seguido de a influência do jornalismo e os Jogos Olímpicos. Rio de Janeiro: Zahar; 1997.

Cecchetto FR. Violência e estilos de masculinidade. Rio de Janeiro: FGV; 2004.

Coche R, Tuggle CA. Men or women, only five olympic sports matter: a quantitative analysis of NBC's prime-time coverage of the Rio Olympics. Electronic News. 2017;12(4):199-217. http://dx.doi.org/10.1177/1931243117739061.

Douglas M. Pureza e perigo. São Paulo: Perspectiva; 2014.

Elias N. Introdução à sociologia. Lisboa: Edições 70; 2005.

Elias N. O processo civilizador, vol. 1: uma história dos costumes. Rio de Janeiro: Zahar; 2011.

Elias N, Dunning E. A busca da excitação. Lisboa: Difel; 1992.

Gastaldo EL. A forja do homem de ferro: a corporalidade nos esportes de combate. In: Leal OF, editor. Corpo e significado: ensaios de Antropologia Social. Porto Alegre: UFRGS; 2001. p. 203-21.

Geertz C. A interpretação das culturas. Rio de Janeiro: Jorge Zahar; 1989.

Latour B. Jamais fomos modernos: ensaio de antropologia simétrica. São Paulo: Ed. 34; 2019.

McClearen J. "We are all fighters": the transmedia marketing of difference in the Ultimate Fighting Championship (UFC). Int J Commun. 2017;11:3224-41.

Nunes CRF. Corpos na arena: um olhar etnográfico sobre a prática das artes marciais mistas [dissertação]. Porto Alegre: Programa de Pós-graduação em Ciências do Movimento Humano da Universidade Federal do Rio Grande do Sul; 2004.

Ozório CE. A desmistificação do lutador de MMA [Internet]. 2020 [citado 2020 Ago 3]. Disponível em: https://www. ufc.com.br/news/desmistificacao-do-lutador-do-ufc

Rial C. Antropologia e mídia: breve panorama das teorias de comunicação. Antropol. Prim. Mao. 2004;9(74):4-74.

Spencer DC. Habit(us), body techniques and body callusing: an ethnography of mixed martial arts. Body Soc. 2009;15(4):119-43. http://dx.doi. org/10.1177/1357034X09347224.

Stake R. Case studies. In: Denzin N, Lincoln Y, editores. Handbook of qualitative research. Newsbury Park: Sage; 1994. p. 236-47.

Vasques DG. As artes marciais mistas como esporte moderno: entre a busca da excitação e a tolerância à violência. Esporte Soc. 2013;8(22):1-23.

Wacquant L. Corpo e alma: notas etnográficas de um aprendiz de boxe. Rio de Janeiro: Relume Dumará; 2002.

Yin R. Estudo de caso: planejamento e métodos. Porto Alegre: Bookman; 2005. 